\title{
Neurotransmitter receptors on microglia
}

\author{
Huan Liu, ${ }^{1}$ Rehana K Leak, ${ }^{2}$ Xiaoming $\mathrm{Hu}^{1}$
}

To cite: Liu H, Leak RK, Hu X. Neurotransmitter receptors on microglia. Stroke and Vascular Neurology 2016;1:e000012. doi:10.1136/svn-2016000012

Received 5 March 2016 Revised 29 April 2016 Accepted 30 April 2016 Published Online First 24 May 2016

\section{CrossMark}

\author{
${ }^{1}$ Center of Cerebrovascular \\ Disease Research, University \\ of Pittsburgh School of \\ Medicine, Pittsburgh, \\ Pennsylvania, USA \\ ${ }^{2}$ Division of Pharmaceutical \\ Sciences, Duquesne \\ University, Pittsburgh, \\ Pennsylvania, USA \\ Correspondence to \\ Dr Xiaoming $\mathrm{Hu}$; \\ hux2@upmc.edu or \\ Dr Rehana Leak; \\ leakr@duq.edu
}

\begin{abstract}
As the resident immune cells in the central nervous system, microglia have long been hypothesised to promote neuroinflammation and exacerbate neurotoxicity. However, this traditional view has undergone recent revision as evidence has accumulated that microglia exert beneficial and detrimental effects depending on activation status, polarisation phenotype and cellular context. A variety of neurotransmitter receptors are expressed on microglia and help mediate the bidirectional communication between neurons and microglia. Here we review data supporting the importance of neurotransmitter receptors on microglia, with a special emphasis on glutamate, $\gamma$-aminobutyric acid (GABA), norepinephrine, cannabinoid and acetylcholine receptors. We summarise evidence favouring a significant role for neurotransmitter receptors in modulating microglial activation, phagocytic clearance and phenotypic polarisation. Elucidating the effects of neurotransmitter receptors on microglia and dissecting the underlying mechanisms may help accelerate the discovery of novel drugs that tap the therapeutic potential of microglia.
\end{abstract}

Microglia, the dynamic, motile phagocytes of the central nervous system, were traditionally viewed as proinflammatory cells that promote neuronal toxicity and death. However, this view failed to account for the dualistic roles that microglia play-roles that are profoundly shaped by existing physiological or pathological cellular conditions. Recent studies suggest that microglia are a double-edged sword, exerting toxic and beneficial roles depending on their polarisation phenotype, activation status and the cellular context. ${ }^{1}$ In addition to the previous overly simplistic view of microglia, neurons were often portrayed as passive victims of microglial activation. However, this view has also undergone revision because communication between these two cell types actually flows in both directions. ${ }^{2}$ First, it has been established that the quiescent state of microglia in the healthy brain is controlled, at least in part, by neuronal factors, such as CD200, as indicated from elevated microglial activation induced by knockout of neuronal CD200. ${ }^{3}$ Second, neuron-specific injury is known to activate nearby microglia that are associated with the damaged neurons. For example, nerve injury specifically in the peripheral nervous system activates those microglia located at the innervation site of the damaged nerve in the central nervous system. ${ }^{4}$ These observations support the view that neurons communicate their health status to the appropriate microglia. Presumably, the microglial recipients of neuron-derived information in turn influence neuronal viability in positive and negative feedback loops, consistent with their dualistic roles in health and disease. However, even though microglia promote neuronal loss in some models, this glial behaviour probably originally evolved for the efficient removal of irreparably injured, highly dysfunctional cells to prevent further damage to the organism as a whole. Indeed, the bidirectional nature of microglial-neuronal communication might be the foundation for healthy crosstalk between neurons and glia before a final decision about neuronal life or death is agreed on and executed by both cell types. Thus, the toxic and protective properties of microglia may have evolved to increase the overall fitness of the entire organism and promote survival. However, one might speculate that this bidirectional neuronal-glial communication system is compromised in disease states so that the toxic properties of overactive microglia overwhelm neighbouring neurons and lead to their unnecessary destruction. Thus, experimental manipulations that interfere with neuronal-glial intercellular communication can be either neurotoxic or neuroprotective in various disease models, as described further below.

One piece of evidence favouring bidirectional neuronal-microglial communication is the presence of numerous types of neurotransmitter receptors on microglia. As neurons generally release neurotransmitters during synaptic activity, this finding suggests that interneuronal communication can also have indirect effects on the neighbouring microglia that surround the active synapse. Furthermore, if Agnati and Fuxe's classic concept of long-distance communication 
through "volume transmission" ${ }^{5}$ can be applied to microglia, one might speculate that even those microglia far away from the active synapse may be the recipients of neuroactive signals that have diffused over a considerable distance. This raises the possibility that microglia respond to neurotransmitters from near and far, collect and synthesise this information and communicate back to neurons in a large-scale feedback loop.

Microglia are well known to express receptors for glutamate as well as many other neurotransmitters. ${ }^{6-8}$ In response to neurotransmitter binding, microglia may increase or decrease their release of neuroactive molecules as part of a positive or negative feedback loop, respectively. The molecules released by microglia in response to neurotransmitter stimulation include free radicals such as superoxide and nitric oxide as well as chemokines and cytokines such as interleukins (ILs) and tumour necrosis factor- $\alpha$ (TNF $\alpha)$, all of which are well known to exert profound effects on neurons. For example, microglial neurotransmitter receptors are known to trigger superoxide production by nicotinamide adenine dinucleotide phosphate (NADPH) oxidase, and this can be either neuroprotective or neurotoxic depending on the neurotransmitter that originally stimulated the microglial receptor. ${ }^{9}$ The bidirectional flow of communication between neurons and microglia is especially well reflected in the tight coupling of the activation of neuronal ion channels to microglial activation. ${ }^{10}$ In general, the 'on' signal is hypothesised to trigger receptor-mediated microglial activation, whereas the 'off' signal serves to contain microglia and keeps them in the default, non-activated state. ${ }^{10}$ Neurotransmitter binding could force microglia down either path depending on the needs of the organism.

Below we summarise some of the evidence in support of neurotransmitter effects on microglia, with special emphasis on glutamate, $\gamma$-aminobutyric acid (GABA), norepinephrine, cannabinoid and acetylcholine receptors. It is evident from the summary below that there are numerous examples of microglia engaging in either protective or toxic behaviours.

\section{GLUTAMIATERGIC MICROGLIAL RECEPTORS}

Glutamate receptors are classified by their binding to well-studied ligands and can be divided into ionotropic or metabotropic receptors. Ionotropic glutamate receptors are cation-specific ion channels, whereas metabotropic glutamate receptors are a family of $G$ proteincoupled, seven transmembrane domain receptors that impact second messenger systems as well as ion channels. Ionotropic glutamate receptors are classified into $\alpha$-amino-3-hydroxy-5-methyl-4-isoxazolepropionic acid (AMPA), kainate or N-methyl-D-aspartate (NMDA) subtypes according to their pharmacological binding properties. Metabotropic glutamate receptors are divided into three groups (groups I, II and III) and eight subtypes
(mGlu1-8) based on their pharmacological characteristics, amino acid sequence similarities and downstream signal transduction cascades. Group I includes mGlu1 and mGlu5, group II includes mGlu2 and mGlu3 and group III includes mGlu4, mGlu6, mGlu7 and mGlu8. The microglial response to glutamate is complex and mediated by ionotropic and metabotropic receptors.

The ionotropic glutamate receptors on microglia include AMPA-type GluR1-GluR4 receptors as well as kainate receptors. ${ }^{6}$ The AMPA receptors on microglia inhibit $\mathrm{TNF} \alpha$ release, whereas glutamate and kainate increase TNF $\alpha$ release. ${ }^{11}$ However, some studies have noted that activation of AMPA receptors on microglia can also stimulate TNF $\alpha$ release. ${ }^{6}$ The impact of TNF $\alpha$ release from microglia is discussed further below. There is also evidence supporting the presence of NMDA receptors on microglia. For example, microglia are transiently activated following injections of NMDA into the cortex of neonatal rats. ${ }^{12}$ Furthermore, NMDA receptor subunits have been identified on microglia, and these receptors may enhance the release of TNF $\alpha$, IL-1 and nitric oxide. $^{13}$

Microglia express members of all three groups of metabotropic glutamate receptors. ${ }^{14-16}$ For example, cultured microglia express group I mGlu5a receptor protein, and activation of this receptor reduces microglial TNF $\alpha$ production. ${ }^{14}$ Microglia also express group II mGlu2 and mGlu3 receptor messenger RNA (mRNA) and protein, and these receptors are both negatively coupled to adenylate cyclase. ${ }^{15}$ The group II receptors are known to activate microglia, leading to enhanced staining for the ED1 microglial activation marker. $^{16}$

Group II microglial glutamate receptors are indirectly activated by $\beta$-amyloid and chromogranin $\mathrm{A}$, both of which accumulate in senile plaques in Alzheimer's disease. $\beta$-Amyloid and chromogranin A elicit the release of microglial glutamate, which, in turn, may bind the group II metabotropic glutamate receptors in microglia in an autologous feedback loop and enhance their toxicity. ${ }^{15}$ Thus, agonists of group II receptors are thought to induce a neurotoxic phenotype in microglia, whereas antagonists of these receptors have been shown to blunt chromogranin A-induced microglial reactivity and neurotoxicity. ${ }^{15}$

Microglia also express group III receptors mGlu4, mGlu6 and mGlu8, but not mGlu7. ${ }^{16}$ In contrast with group II receptors, the activation of group III mGlu receptors induces mild activation of microglia-as evidenced by enhanced ED1 staining-but this activation is not neurotoxic. ${ }^{16}$ Activation of group III mGlu receptors prevents microglial release of glutamate, ${ }^{8}$ reduces microglial reactivity in response to lipopolysaccharide (LPS) and $\beta$-amyloid and prevents microglial toxicity towards neurons. ${ }^{16}$ These latter findings suggest that activation of group III mGlu receptors may serve as a potentially therapeutic means to blunt neuroinflammation. Taken together, the studies on metabotropic glutamate 
receptors suggest that the impact of mGlu receptor activation on microglial reactivity and neurotoxicity depends on the receptor subtype; group II receptor activation may be toxic, but group III receptor activation may be protective (figure 1).

Despite the above-mentioned observations on group II metabotropic receptors, activation of group II receptors in microglia is not inevitably toxic. For example, intrastriatal injections of an agonist for group II receptors, DCG-IV ((2S,2'R,3'R)-2-(2'3'-dicarboxycyclopropyl) glycine), markedly activate microglia but nevertheless protect dopaminergic terminals against the parkinsonian toxicant 1-methyl-4-phenylpyridinium $\left(\mathrm{MPP}^{+}\right) .{ }^{17}$ Striatal cells in this model also upregulate brain-derived neurotrophic factor (BDNF). Although DCG-IV protects dopamine neurons, it is actually toxic to cells in the striatum. ${ }^{18}$ These findings reveal that microglial activation may be associated with diverse effects on various cell types. In sum, the impact of glutamatergic receptor activation on microglia appears to vary depending on receptor
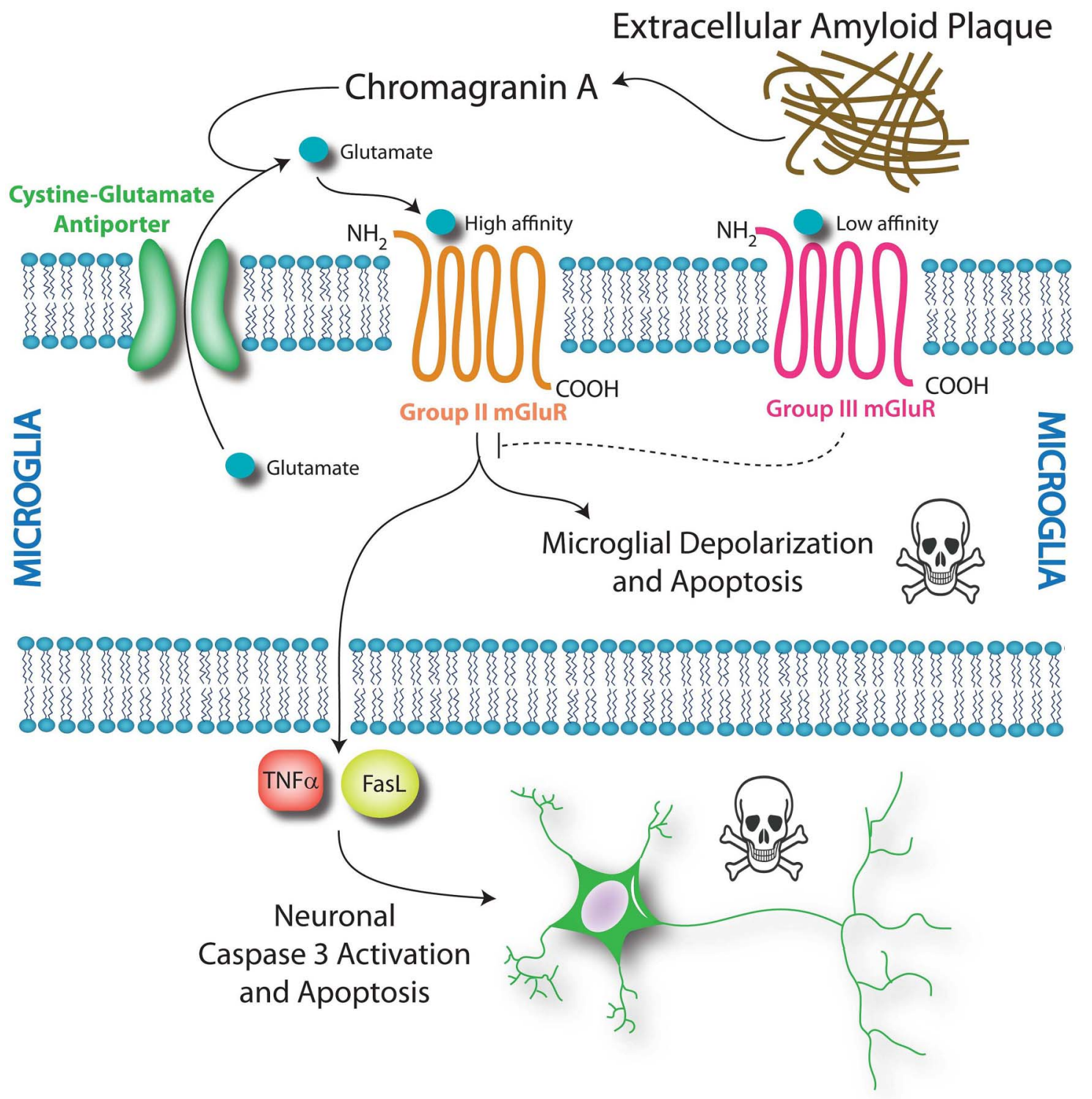

Figure 1 Metabotropic glutamate receptors impact microglial and neuronal survival. Chromogranin A from senile plaques is hypothesised to enhance the release of glutamate from microglial stores via the cystine-glutamate antiporter. This glutamate may bind to high-affinity group II mGluRs and initiate microglial cell death via depolarisation and apoptosis. A second effect of group II mGluR activation is microglial toxicity towards neurons. Activation of the group II mGluR receptor induces tumour necrosis factor- $\alpha(T N F \alpha)$ release from microglia. This TNF $\alpha$ is neurotoxic in the presence of Fas ligand (FasL), which is also derived from microglia. These two soluble molecules stimulate caspase-mediated neuronal apoptosis via the TNF receptor TNFR1. In contrast, activation of the low-affinity group III mGlu receptors does not induce microglial apoptosis. Instead, group III activation reduces microglial reactivity in response to chromogranin $\mathrm{A}$ and attenuates microglial toxicity towards neurons. Thus, modulation of microglial metabotropic glutamate receptors may be a pharmacological means to control microglial activation and impact neuronal survival. 
subtype, cellular phenotype as well as the type of stimulus (such as $\mathrm{MPP}^{+}$vs chromogranin $\mathrm{A}$ ).

As with ionotropic receptors, other effects of metabotropic glutamate receptor activation in microglia include changes in TNF $\alpha$ release. ${ }^{6}{ }^{11}$ Although activation of group I receptors reduces $\mathrm{TNF} \alpha$ production in cultured microglia, ${ }^{14}$ stimulation of mGlu2 triggers $\mathrm{TNF} \alpha$-induced neurotoxicity associated with the Fas death receptor ligand. ${ }^{19}$ Fas ligand released in this manner activates caspase 3 in neurons via p55 and thereby elicits neuronal death (figure 1). Under these conditions, TNF $\alpha$ is only neurotoxic in the presence of microglia or microgliaconditioned medium because Fas ligand must also be present. ${ }^{19}$ Thus, glutamate receptor activation in microglia may kill neighbouring neurons in a $\mathrm{TNF} \alpha /$ Fas liganddependent and caspase-dependent manner. It should be noted, however, that TNF $\alpha$ and IL-6 may also be neuroprotective, particularly under ischaemic conditions. ${ }^{20} 21$ Therefore, the impact of glutamate receptor activation on microglia might have more subtle and varied effects than anticipated.

\section{GABAERGIC MICROGLIAL RECEPTORS}

GABA is the major inhibitory transmitter in the central nervous system and binds to one of the two types of receptors- $\mathrm{GABA}_{\mathrm{A}}$ and $\mathrm{GABA}_{\mathrm{B}}$. $\mathrm{GABA}_{\mathrm{A}}$ receptors are ionotropic, whereas $\mathrm{GABA}_{\mathrm{B}}$ receptors are metabotropic. Both groups of receptors are divided into subtypes. Microglia express all three subtypes of $\mathrm{GABA}_{\mathrm{B}}$ receptors in culture and in vivo, supporting the hypothesis that microglia are cellular targets for the GABA neurotransmitter. ${ }^{22}$ There is some evidence to suggest that these receptors modulate the release of proinflammatory microglial cytokines such as ILs in response to GABAergic tone. For example, $\mathrm{GABA}_{\mathrm{B}}$ receptor agonists trigger the induction of an outwardly rectifying $\mathrm{K}^{+}$conductance in microglia and attenuate the LPS-induced release of microglial cytokines such as IL-6 and IL-12p $40 .^{22}$ In contrast, the $\mathrm{GABA}_{\mathrm{B}}$ receptor did not affect $\mathrm{TNF} \alpha$ or nitric oxide secretion in these studies.

It is noteworthy that microglia increase their expression of $\mathrm{GABA}_{\mathrm{B}}$ receptors in response to injuries. ${ }^{22}$ Given the $\mathrm{GABA}_{\mathrm{B}}$ receptor-induced attenuation of microglial IL secretion, this compensatory increase in receptors during times of stress may reflect the generally protective role of the inhibitory GABA neurotransmitter. This view is consistent with reports that GABA promotes a neuroprotective phenotype in microglia. ${ }^{9}$

Microglia also express $\mathrm{GABA}_{\mathrm{A}}$ receptors. GABA receptors trigger microglial superoxide production and promote a neuroprotective microglial phenotype. ${ }^{9}$ The $\mathrm{GABA}_{\mathrm{A}}$ receptor agonist muscimol inhibits the LPS-induced release of TNF $\alpha$ and IL-6 from microglia. ${ }^{23}$ Microglia may also indirectly respond to muscimol, as this $\mathrm{GABA}_{\mathrm{A}}$ agonist stimulates neuronal and macroglial $\mathrm{GABA}_{\mathrm{A}}$ receptors and increases extracellular $\mathrm{K}^{+}$concentrations. This increase in $\mathrm{K}^{+}$, in turn, causes microglia to release chemokines such as macrophage inflammatory protein-1 $\alpha(\mathrm{MIP} 1 \alpha) .{ }^{24}$ Thus, microglia can respond directly and indirectly to GABAergic tone.

\section{NOREPINEPHRINE MICROGLIAL RECEPTORS}

Catecholamines such as norepinephrine and epinephrine bind to $\mathrm{G}$ protein-coupled adrenergic receptors, usually eliciting a sympathomimetic response. There are two main groups of adrenergic receptors, $\alpha$ and $\beta$, and each group contains multiple subtypes with homologous sequences. The $\alpha$ group contains $\alpha 1$ and $\alpha 2$ subtypes, which increase inositol triphosphate and diacylglycerol or decrease cyclic AMP, respectively. The $\beta$ group contains $\beta 1, \beta 2$ and $\beta 3$ subtypes and is generally linked to activation of adenylate cyclase and subsequent increases in intracellular cyclic AMP. Many research groups have established the presence of adrenergic receptors on microglia. ${ }^{25}$ Norepinephrine and $\beta 1$-adrenergic agonists generally increase cyclic AMP levels in microglia. ${ }^{26} 27$ Therefore, it is not surprising that forskolin, a cyclic AMP-elevating agent, can mimic some of the effects of $\beta$-adrenergic agonists on microglia. ${ }^{27}$

Microglial cells express mRNAs encoding $\alpha 1 \mathrm{~A}, \alpha 2 \mathrm{~A}, \beta 1$ and $\beta 2$ receptors. ${ }^{26}$ Agonism at these receptors appears to dampen microglial reactivity. For example, the toxicity of microglia can be downregulated by $\beta$-adrenergic agonists. ${ }^{25}$ Furthermore, norepinephrine and $\beta 1$-adrenergic agonists suppress the production of proinflammatory cytokines such as IL-6 and TNF $\alpha .{ }^{26}{ }^{28}$ In line with the dampening of microglial activation, catecholamines also inhibit nitric oxide production from microglia, perhaps by causing a decrease in inducible nitric oxide synthase. ${ }^{28} 29$ These findings reveal that free radical production from microglia is attenuated by the action of catecholamines on adrenergic receptors. Owing to their attenuation of free radical and cytokine release, adrenergic agonists present a means to mitigate the cytotoxicity of microglia. It is also noteworthy that depletion of adrenergic tone negatively affects the microglial phagocytic clearance of $\beta$-amyloid. ${ }^{30}$ Thus, catecholaminergic tone in the brain may modulate inflammation in a protective way.

\section{CANNABINOID MICROGLIAL RECEPTORS}

Cannabinoid receptors are $\mathrm{G}$ protein-coupled receptors that bind to tetrahydrocannabinol (THC), the major psychoactive ingredient in marijuana. These receptors have evolved to respond to endocannabinoids, endogenous ligands that include anandamide. Cannabinoid receptors are divided into two groups, CB1 and CB2. It is the CB2 receptor subtype that is primarily expressed in microglia. ${ }^{31}$ Endocannabinoids can regulate microglial reactivity by binding to CB2 and inhibiting adenylate cyclase. ${ }^{32}$ This microglial receptor is overexpressed in neuroinflammatory disorders, as discussed below. ${ }^{31}$ CB2 receptor activation stimulates microglial migration but inhibits the release of cytokines such as IL-6 and 
TNFo. ${ }^{32}$ Thus, it is not surprising that CB2 agonists have been shown to be protective in several experimental models of diseases. For example, the CB2 agonist JWH-015 improves motor function under the demyelinating conditions induced by Theiler's murine encephalomyelitis virus. ${ }^{33}$ Another CB2 agonist, JWH-133, significantly decreases the immunostaining intensity of Iba1+ activated microglia and blunts the expression of proinflammatory factors such as IL-6, TNF $\alpha$ and inducible nitric oxide synthase (iNOS) in a mouse model of stroke. These effects are reversed by inhibition of CB2R or absent in CB2R knockout mice. ${ }^{34}$ Pretreatment with AM1241, another CB2 agonist, has also been reported to attenuate LPS plus interferon $\gamma$ (IFN $\gamma$ )-induced microglial activation by shifting microglial polarisation from the toxic M1 state to the protective M2 state. ${ }^{35}$ In models of Alzheimer's disease, the endocannabinoid system may be similarly protective. For example, the CB1/CB2 agonist WIN55 inhibits $\beta$-amyloid-mediated activation of microglia in vitro and $\beta$-amyloid-mediated toxicity in vivo. ${ }^{36}$ Furthermore, overexpression of CB2R reduces the immunostaining intensity of Iba1+ activated microglia and results in neuroprotection against the 6hydroxydopamine model of Parkinson's disease. ${ }^{37}$

Given the above-mentioned findings that CB2 receptors may be protective against multiple disease states, it is not surprising that CB2 knockout animals are, conversely, more vulnerable in several models of human diseases. For example, CB2 gene ablation increases 1-methyl-4-phenyl-1,2,3,6-tetrahydropyridine (MPTP) toxicity in models of Parkinson's disease. ${ }^{38}$ CB2 knockout animals also show increased microglial activation and greater axonal loss in the inflamed spinal cord. ${ }^{39}$ The endocannabinoid system is thus hypothesised to counteract the progression of disorders such as Huntington's disease, multiple sclerosis, amyotrophic lateral sclerosis and stroke. Perhaps because of its intrinsically protective properties, this system appears to be upregulated under conditions of injury, perhaps as a compensatory response to preserve homeostasis. ${ }^{32}$ For example, upregulation of CB2R has been reported in rat models of Parkinson's disease. ${ }^{40}$ In humans suffering from multiple sclerosis, CB2 expression is increased in the microglia associated with white matter. ${ }^{41}$ The CB2 receptor is also increased postmortem tissue in amyotrophic lateral sclerosis. ${ }^{41}$ In short, the endocannabinoid system may be upregulated in disease states in order to help the brain adapt to pathological stress. This is consistent with reports that activation of CB2R induces an anti-inflammatory phenotype in microglia. ${ }^{37}$

\section{ACETYLCHOLINE MIICROGLIAL RECEPTORS}

Acetylcholine receptors are classified as nicotinic or muscarinic. Nicotinic receptors are ionotropic cation channels permeable to $\mathrm{Na}^{+}$and $\mathrm{K}^{+}$and subdivided into muscle-type and neuronal-type ( $\alpha 2-\alpha 10$ and $\beta 2-\beta 4)$ receptors. Muscarinic receptors are metabotropic G protein-coupled receptors, some of which deactivate adenylate cyclase and activate $\mathrm{K}^{+}$channels $\left(\mathrm{M}_{2}, \mathrm{M}_{4}\right)$, while others upregulate phospholipase $\mathrm{C}$, inositol triphosphate and intracellular calcium $\left(\mathrm{M}_{1}, \mathrm{M}_{3}, \mathrm{M}_{5}\right)$. Nicotinic $\alpha 3, \alpha 5, \alpha 6, \alpha 7$ and $\beta 4$ receptors are expressed in microglia. ${ }^{42}{ }^{43}$ Muscarinic receptors are also expressed in cultured microglia, but far less is known about their function. ${ }^{44}$

The nicotinic $\alpha 7$ receptors on microglia increase intracellular calcium through the inositol triphosphate pathway. ${ }^{45}$ Nicotine increases or decreases microglial $\mathrm{TNF} \alpha$ release in response to purinergic receptor activation or LPS stimulation, respectively. ${ }^{42} 45$ The inhibition of TNF $\alpha$ release from microglia by acetylcholine or nicotine is mediated by a reduction in ERK1/2 and p38 MAP kinase signalling. ${ }^{42}$ In general, nicotinic receptors dampen microglial activation. For example, nicotine reduces free radical production from microglia in response to $\beta$-amyloid. ${ }^{46}$ Nicotinic receptor activation in microglia also inhibits their activation in response to IFN $\gamma .{ }^{47}$ Furthermore, activation of nicotinic $\alpha 7$ receptors induces an increase in antioxidant genes and a decrease in the phosphorylation of nuclear factor kappa B $(\mathrm{NF}-\mathrm{\kappa B})$ and $\mathrm{p} 65$ in microglia, and promotes microglial M2 polarisation. ${ }^{48}$ All of these findings support the view that acetylcholine dampens the immune response of the brain.

\section{OTHER RECEPTORS OF NEUROTRANSMITTERS AND CONCLUSION}

Other types of microglial receptors not covered in the present review include receptors for bradykinin, ${ }^{49}$ dopamine, ${ }^{28}$ purine, ${ }^{49}$ adenosine ${ }^{49}$ and opioids, ${ }^{49}$ among other transmitters. Through these multiple types of neurotransmitter receptors, neurons can actively control microglial function, often, but not always, dampening microglial activation. Conversely, microglia actively control neuronal function in a feedback loop. For example, it has long been known that microglia modulate synaptic plasticity by the secretion of inflammatory mediators, triggering changes in learning and memory and affecting adaptive behaviour. ${ }^{50}$ Given the plasticity of the brain and its inherent ability to respond to challenges, it is not surprising that the flow of communication between these two fundamental cell types is in both directions. As argued earlier, this loop may be part of a phylogenetically ancient design that allows microglia to respond dynamically to the synaptic release of neurotransmitters and control neuronal state to promote survival and organismal fitness.

In summary, microglia are typically quiescent under physiological, healthy conditions but can be rapidly activated under pathological conditions, exerting either toxic or neuroprotective effects in accordance with their polarisation phenotypes. The quiescent state of microglia is maintained, at least partly, by neurotransmitters released from neurons. ${ }^{3}$ For example, a decrease in 


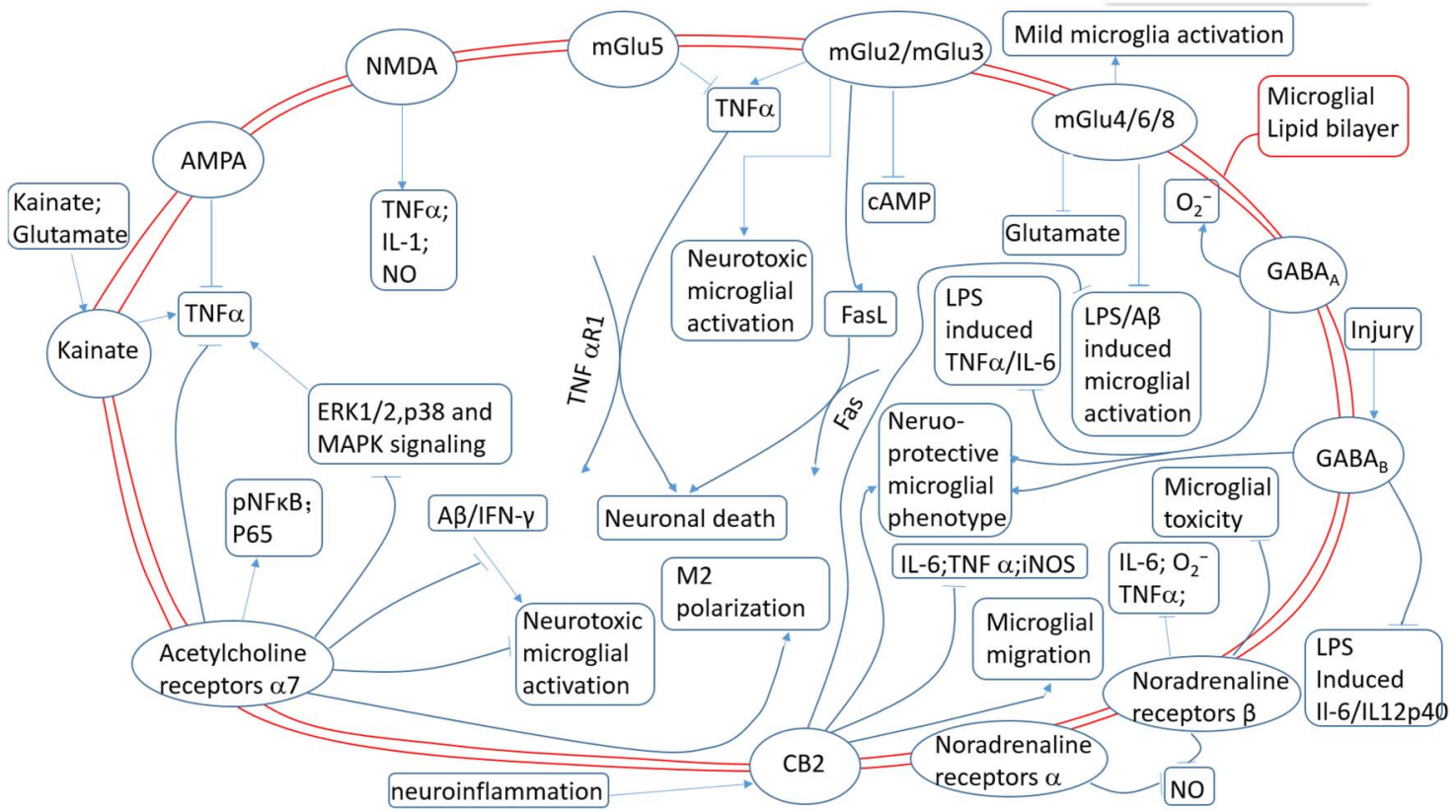

Figure 2 Different effects of various microglial neurotransmitter receptors. AMPA,

$\alpha$-amino-3-hydroxy-5-methyl-4-isoxazolepropionic acid; cAMP, cyclic adenosine monophosphate; ERK, extracellular signal-regulated kinase; FasL, Fas ligand; GABA, $\gamma$-aminobutyric acid; iNOS, inducible nitric oxide synthase; IFN $\gamma$, interferon $\gamma$; IL-1, interleukin 1; IL-6, interleukin 6; LPS, lipopolysaccharide; MAPK, mitogen-activated protein kinase; NMDA, $\mathrm{N}$-methyl-D-aspartate; NO, nitric oxide; $\mathrm{TNF} \alpha$, tumour necrosis factor- $\alpha$.

morphological change and process motility has been observed in retinal microglia after activation of the $\mathrm{GABA}_{\mathrm{A}}$ receptor. ${ }^{51}$ On the other hand, pathological neuronal activity may contribute to the inflammatory milieu of the brain because of the presence of neurotransmitter receptors on microglia. For example, during pathological processes, neurons may release sufficient glutamate to initiate an excitotoxic cascade and activate neighbouring microglia. ${ }^{52}$ Besides exacerbating microglial inflammation and neurotoxicity, activation of microglial neurotransmitter receptors also may induce anti-inflammatory effects by reducing $\mathrm{TNF}^{42}$ and IL- $6,{ }^{22}$ decreasing superoxide ${ }^{53}$ and nitric oxide ${ }^{14}$ production, and thereby eliciting neuroprotective effects. The functional roles of microglial neurotransmitter receptors in the maintenance of microglial quiescence or phenotypic switches are still poorly understood. Also, we have very little information about the interactions between different microglial receptors and their combined downstream effects. Different microglial neurotransmitter receptors might be simultaneously or sequentially activated (figure 2). Although these receptors have been individually studied, the interplay between them remains unknown. In addition, the lack of a specific antibody recognising specifically either microglia or macrophages precluded the possibility of distinguishing between the local microglia and circulating macrophages that were recruited to the injured brain. As a result, many studies regarding the function of microglial neurotransmitter receptors in the injured brain may also include the infiltrated macrophages.
Further research to elucidate the role of microglial receptors and test their therapeutic potential in neurological disorders is urgently needed. ${ }^{54}$

Contributors $\mathrm{HL}$, RKL and XH wrote the manuscript.

Funding This work was supported by the NIH/National Institute of Neurological Disorders and Stroke (NINDS) grants NS092618 (to XH), a grant (13SDG14570025) from the American Heart Association (to XH).

\section{Competing interests None declared.}

Provenance and peer review Not commissioned; externally peer reviewed.

Data sharing statement No additional data are available.

Open Access This is an Open Access article distributed in accordance with the Creative Commons Attribution Non Commercial (CC BY-NC 4.0) license, which permits others to distribute, remix, adapt, build upon this work noncommercially, and license their derivative works on different terms, provided the original work is properly cited and the use is non-commercial. See: http:// creativecommons.org/licenses/by-nc/4.0/

\section{REFERENCES}

1. Hu X, Leak RK, Shi $Y$, et al. Microglial and macrophage polarization-new prospects for brain repair. Nat Rev Neurol 2015;11:56-64

2. Eyo UB, Wu LJ. Bidirectional microglia-neuron communication in the healthy brain. Neural Plast 2013;2013:456857.

3. Hoek RM, Ruuls SR, Murphy CA, et al. Down-regulation of the macrophage lineage through interaction with OX2 (CD200). Science (New York, NY) 2000;290:1768-71.

4. Banati RB. Brain plasticity and microglia: is transsynaptic glial activation in the thalamus after limb denervation linked to cortical plasticity and central sensitisation? J Physiol Paris 2002;96:289-99.

5. Agnati LF, Guidolin D, Guescini M, et al. Understanding wiring and volume transmission. Brain Res Rev 2010;64:137-59. 
6. Noda M, Nakanishi H, Nabekura J, et al. AMPA-kainate subtypes of glutamate receptor in rat cerebral microglia. J Neurosci 2000;20:251-8.

7. Sivakumar V, Ling EA, Lu J, et al. Role of glutamate and its receptors and insulin-like growth factors in hypoxia induced periventricular white matter injury. Glia 2010;58:507-23.

8. McMullan SM, Phanavanh B, Li GG, et al. Metabotropic glutamate receptors inhibit microglial glutamate release. ASN Neuro 2012;4.

9. Mead EL, Mosley A, Eaton S, et al. Microglial neurotransmitter receptors trigger superoxide production in microglia; consequences for microglial-neuronal interactions. $J$ Neurochem 2012;121:287-301.

10. Kettenmann $\mathrm{H}$, Hanisch UK, Noda M, et al. Physiology of microglia. Physiol Rev 2011;91:461-553.

11. Hagino $Y$, Kariura $Y$, Manago $Y$, et al. Heterogeneity and potentiation of AMPA type of glutamate receptors in rat cultured microglia. Glia 2004;47:68-77.

12. Acarin L, González B, Castellano B, et al. Microglial response to $\mathrm{N}$-methyl-D-aspartate-mediated excitotoxicity in the immature rat brain. J Comp Neurol 1996;367:361-74.

13. Murugan M, Sivakumar V, Lu J, et al. Expression of N-methyl $\mathrm{D}$-aspartate receptor subunits in amoeboid microglia mediates production of nitric oxide via NF-kappaB signaling pathway and oligodendrocyte cell death in hypoxic postnatal rats. Glia 2011;59:521-39.

14. Byrnes KR, Stoica B, Loane DJ, et al. Metabotropic glutamate receptor 5 activation inhibits microglial associated inflammation and neurotoxicity. Glia 2009;57:550-60.

15. Taylor DL, Diemel LT, Cuzner ML, et al. Activation of group II metabotropic glutamate receptors underlies microglial reactivity and neurotoxicity following stimulation with chromogranin $A$, a peptide up-regulated in Alzheimer's disease. J Neurochem 2002;82:1179-91.

16. Taylor DL, Diemel LT, Pocock JM. Activation of microglial group III metabotropic glutamate receptors protects neurons against microglial neurotoxicity. J Neurosci 2003;23:2150-60.

17. Matarredona ER, Santiago M, Venero JL, et al. Group II metabotropic glutamate receptor activation protects striatal dopaminergic nerve terminals against MPP+-induced neurotoxicity along with brain-derived neurotrophic factor induction. J Neurochem 2001;76:351-60.

18. Venero JL, Santiago M, Tomas-Camardiel M, et al. DCG-IV but not other group-II metabotropic receptor agonists induces microglial BDNF mRNA expression in the rat striatum. Correlation with neuronal injury. Neuroscience 2002;113:857-69.

19. Taylor DL, Jones F, Kubota ES, et al. Stimulation of microglial metabotropic glutamate receptor mGlu2 triggers tumor necrosis factor alpha-induced neurotoxicity in concert with microglial-derived Fas ligand. J Neurosci 2005;25:2952-64.

20. Cheng B, Christakos S, Mattson MP. Tumor necrosis factors protect neurons against metabolic-excitotoxic insults and promote maintenance of calcium homeostasis. Neuron 1994;12 139-53.

21. Loddick SA, Turnbull AV, Rothwell NJ. Cerebral interleukin-6 is neuroprotective during permanent focal cerebral ischemia in the rat. $J$ Cereb Blood Flow Metab 1998;18:176-9.

22. Kuhn SA, van Landeghem FK, Zacharias R, et al. Microglia express $\mathrm{GABA}(\mathrm{B})$ receptors to modulate interleukin release. $\mathrm{Mol} \mathrm{Ce} / \mathrm{l}$ Neurosci 2004;25:312-22.

23. Lee M, Schwab C, McGeer PL. Astrocytes are GABAergic cells that modulate microglial activity. Glia 2011;59:152-65.

24. Cheung G, Kann O, Kohsaka S, et al. GABAergic activities enhance macrophage inflammatory protein-1alpha release from microglia (brain macrophages) in postnatal mouse brain. J Physiol (Lond) 2009;587(Pt 4):753-68.

25. Théry $\mathrm{C}$, Dobbertin A, Mallat M. Downregulation of in vitro neurotoxicity of brain macrophages by prostaglandin E2 and a beta-adrenergic agonist. Glia 1994;11:383-6.

26. Mori $\mathrm{K}$, Ozaki $\mathrm{E}$, Zhang $\mathrm{B}$, et al. Effects of norepinephrine on rat cultured microglial cells that express alpha1, alpha2, beta1 and beta2 adrenergic receptors. Neuropharmacology 2002;43:1026-34.

27. Prinz M, Häusler KG, Kettenmann $\mathrm{H}$, et al. beta-adrenergic receptor stimulation selectively inhibits IL-12p40 release in microglia. Brain Res 2001;899:264-70.

28. Färber K, Pannasch U, Kettenmann H. Dopamine and noradrenaline control distinct functions in rodent microglial cells. Mol Cell Neurosci 2005;29:128-38.

29. Chang JY, Liu LZ. Catecholamines inhibit microglial nitric oxide production. Brain Res Bull 2000;52:525-30.

30. Heneka MT, Nadrigny F, Regen T, et al. Locus ceruleus controls Alzheimer's disease pathology by modulating microglial functions through norepinephrine. Proc Natl Acad Sci USA 2010;107:6058-63.

31. Miller AM, Stella N. CB2 receptor-mediated migration of immune cells: it can go either way. Br J Pharmacol 2008;153:299-308.

32. Bisogno T, Di Marzo V. Cannabinoid receptors and endocannabinoids: role in neuroinflammatory and neurodegenerative disorders. CNS Neurol Disord Drug Targets 2010;9:564-73.

33. Arévalo-Martín A, Vela JM, Molina-Holgado E, et al. Therapeutic action of cannabinoids in a murine model of multiple sclerosis. J Neurosci 2003;23:2511-16.

34. Zarruk JG, Fernandez-Lopez D, Garcia-Yebenes I, et al. Cannabinoid type 2 receptor activation downregulates stroke-induced classic and alternative brain macrophage/microglia activation concomitant to neuroprotection. Stroke 2012;43:211-19.

35. Ma L, Jia J, Liu X, et al. Activation of murine microglial N9 cells is attenuated through cannabinoid receptor CB2 signaling. Biochem Biophys Res Commun 2015;458:92-7.

36. Ramirez BG, Blazquez C, Gomez del Pulgar T, et al. Prevention of Alzheimer's disease pathology by cannabinoids: neuroprotection mediated by blockade of microglial activation. J Neurosci 2005;25:1904-13

37. Ternianov A, Perez-Ortiz JM, Solesio ME, et al. Overexpression of CB2 cannabinoid receptors results in neuroprotection against behavioral and neurochemical alterations induced by intracaudate administration of 6-hydroxydopamine. Neurobiol Aging 2012;33:421. e1-16.

38. Price DA, Martinez AA, Seillier A, et al. WIN55,212-2, a cannabinoid receptor agonist, protects against nigrostriatal cell loss in the 1-methyl-4-phenyl-1,2,3,6-tetrahydropyridine mouse model of Parkinson's disease. Eur J Neurosci 2009;29:2177-86.

39. Palazuelos J, Davoust N, Julien B, et al. The CB(2) cannabinoid receptor controls myeloid progenitor trafficking: involvement in the pathogenesis of an animal model of multiple sclerosis. J Biol Chem 2008;283:13320-9.

40. Concannon RM, Okine BN, Finn DP, et al. Differential upregulation of the cannabinoid $\mathrm{CB}(2)$ receptor in neurotoxic and inflammation-driven rat models of Parkinson's disease. Exp Neurol 2015;269:133-41

41. Yiangou $Y$, Facer $P$, Durrenberger $P$, et al. COX-2, CB2 and $\mathrm{P} 2 \mathrm{X} 7$-immunoreactivities are increased in activated microglial cells/ macrophages of multiple sclerosis and amyotrophic lateral sclerosis spinal cord. BMC Neurol 2006;6:12.

42. Shytle RD, Mori T, Townsend $\mathrm{K}$, et al. Cholinergic modulation of microglial activation by alpha 7 nicotinic receptors. J Neurochem 2004;89:337-43.

43. Liu J, McGlinn AM, Fernandes A, et al. Nicotinic acetylcholine receptor subunits in rhesus monkey retina. Invest Ophthalmol Vis Sci 2009:50:1408-15

44. Zhang L, McLarnon JG, Goghari V, et al. Cholinergic agonists increase intracellular $\mathrm{Ca} 2+$ in cultured human microglia. Neurosci Lett 1998;255:33-6.

45. Suzuki T, Hide I, Matsubara A, et al. Microglial alpha7 nicotinic acetylcholine receptors drive a phospholipase C/IP3 pathway and modulate the cell activation toward a neuroprotective role. J Neurosci Res 2006;83:1461-70.

46. Moon JH, Kim SY, Lee HG, et al. Activation of nicotinic acetylcholine receptor prevents the production of reactive oxygen species in fibrillar beta amyloid peptide (1-42)-stimulated microglia. Exp Mol Med 2008;40:11-18.

47. Giunta B, Ehrhart J, Townsend K, et al. Galantamine and nicotine have a synergistic effect on inhibition of microglial activation induced by HIV-1 gp120. Brain Res Bull 2004;64:165-70.

48. Han Z, Shen F, He Y, et al. Activation of alpha-7 nicotinic acetylcholine receptor reduces ischemic stroke injury through reduction of pro-inflammatory macrophages and oxidative stress. PLOS ONE 2014;9:e105711.

49. Pocock JM, Kettenmann $\mathrm{H}$. Neurotransmitter receptors on microglia. Trends Neurosci 2007;30:527-35.

50. Ben Achour S, Pascual O. Glia: the many ways to modulate synaptic plasticity. Neurochem Int 2010;57:440-5.

51. Fontainhas AM, Wang M, Liang KJ, et al. Microglial morphology and dynamic behavior is regulated by ionotropic glutamatergic and GABAergic neurotransmission. PLOS ONE 2011;6:e15973.

52. Farber K, Kettenmann H. Physiology of microglial cells. Brain Res Rev 2005:48:133-43.

53. Colton CA, Chernyshev ON. Inhibition of microglial superoxide anion production by isoproterenol and dexamethasone. Neurochem Int 1996;29:43-53.

54. Derecki NC, Katzmarski N, Kipnis J, et al. Microglia as a critical player in both developmental and late-life CNS pathologies. Acta Neuropathol 2014;128:333-45. 